\title{
Psychosis and academic performance
}

\author{
JON L. KARLSSON
}

\begin{abstract}
Background It has been suggested that psychosis genes might be associated with beneficial effects, explaining their high frequency in all human populations.
\end{abstract}

Aims To test the relationship between academic success and the incidence of psychotic disorders.

\begin{abstract}
Method The unusually complete demographic and scholastic records available in Iceland were used to locate academically accomplished individuals and assess the probability of previously identified patients with mental disorders and their relatives being among such groups.
\end{abstract}

Results Close relatives of successful students showed increased risks of psychosis. Individuals who subsequently developed psychosis and relatives of people with psychosis excelled in school performance, particularly in mathematics.

Conclusions The study supports the hypothesis that stimulation associated with psychotic tendencies enhances performance in academic settings.

\section{Declaration of interest None.}

Many authors have presented evidence suggesting an increased risk of mental illness in creative artists and their relatives (LangeEichbaum, 1931; Goodwin \& Jamison, 1990). Few such studies have been made of highly successful scholars, although there are also indications of elevated rates of psychosis in their ranks (Isohanni et al, 1999). A unique opportunity exists in Iceland for a quantitative investigation of high-scoring graduates of the special university preparatory schools, evaluating the students' comparative risk, as well as that of their relatives, of eventually requiring hospital treatment for serious mental disorders.

\section{METHOD}

This study is an extension of a large investigation of family risks of psychosis first published 30 years ago (Karlsson, 1974). This investigation embraced the entire population of Iceland born in the period 1851-1940 and surviving past the age of 15 years. For statistical purposes the material was divided into three generations, according to the year of birth: 1851-1880, 1881-1910 and 1911-1940. In these 30year periods surviving births in Iceland (estimated from official records) were 45000,56000 and 70000 , respectively, rounded to the nearest thousand. Rates for each generation of ever having been admitted (by 1968) for treatment of endogenous psychosis to the single mental hospital serving the whole country were established for the general population, ranging from $0.4 \%$ to $1.2 \%$. Detailed comparative tables (Karlsson, 1988) demonstrated that the risks of psychosis in parents, full siblings and children of people who had been so admitted increased approximately four-fold. This research material was further analysed according to hospital diagnosis of the patients and corresponding illnesses in their relatives. The excellent local demographic records and stability of the population made such a study feasible.

The investigation was then expanded to include assessment of the academic success of individuals who later developed psychosis and first-degree relatives of patients, again comparing them with the population at large. The records of Icelandic university preparatory schools have been published annually and are available for inspection at the National Library in Reykjavik. They include the names and birth dates of all graduates and the actual grade point scores achieved in each subject by every individual in the final examinations at age 20 years. During the first two intervals, comprising the graduation years 1871-1930, there was just one 'gymnasium' type educational institution in Iceland, located in Reykjavik, in which all students followed the same curriculum. In the last period, 1931-1960, a second similar school operated in Akureyri in north Iceland. The parents, full siblings and children of the graduating students, also born in the interval 18511940, have been identified with records at the National Archives.

For an initial exploration, the top graduates each year, born 1851-1910, were selected, on the basis of the highest grade point average achieved at age 20 years. The two top graduates from the single school were selected for those born 18511910, and for those born 1911-1940 the top male graduate from each of the two schools was chosen. Thus, there were in this survey 180 index scholars, approximately $0.1 \%$ of the total population of 171000 ; all were male. These individuals and their relatives were then evaluated for rates of ever having been admitted to the mental hospital, comparing their risk of hospital-treated psychosis with the figure of just under $1 \%$ already established for the general population. The expected numbers of such patients among the graduates and their relatives were computed separately for each generation according to the basic data (Karlsson, 1988) and then added together. Since it was only in the third study period that young women started attending advanced schools in significant numbers, a similar longitudinal study of women was not feasible.

A second investigation was limited to the generation born 1911-1940, selecting for assessment of mental disease the firstdegree relatives of the three highest graduates in terms of overall grades each year, separately for each gender, at Reykjavik College 
Table I Risks of hospital-treated psychosis in top graduates and their relatives, $v$. academic success among people with psychotic disorders and their relatives, both evaluated in terms of corresponding rates in the general population

\begin{tabular}{|c|c|c|c|c|c|c|}
\hline \multirow[t]{2}{*}{ Relationship } & \multicolumn{3}{|c|}{ Cases of psychosis in families of achievers } & \multicolumn{3}{|c|}{ Top graduates in affected families } \\
\hline & $n$ & Expected & Observed & $n$ & Expected & Observed \\
\hline Index cases & 180 & $\mathrm{I} .4$ & 4 & 1377 & $\mathrm{I} .4$ & 4 \\
\hline Parents & 223 & 1.6 & 3 & 2261 & 2.7 & 6 \\
\hline Full siblings & 516 & 4.1 & 13 & 5611 & 5.6 & 14 \\
\hline \multirow[t]{2}{*}{ Children } & 277 & 2.7 & 6 & 1507 & 1.4 & 3 \\
\hline & \multicolumn{3}{|c|}{$\chi^{2}=26.4, P<0.01$} & \multicolumn{3}{|c|}{$\chi^{2}=21.3, P<0.01$} \\
\hline
\end{tabular}

Table 2 Rates of psychosis in first-degree relatives of the highest performers in Reykjavik College in the years $1931-1960$

\begin{tabular}{lccc}
\hline Index scholars & \multicolumn{3}{c}{ Relatives born 188I-1940 } \\
\cline { 2 - 4 } & $n$ & $\begin{array}{c}\text { Expected } \\
\text { rate }\end{array}$ & $\begin{array}{c}\text { Observed } \\
\text { rate }\end{array}$ \\
& & & \\
\hline $\begin{array}{l}\text { Humanities section } \\
\text { Males }(n=90)\end{array}$ & 338 & 3.3 & 4 \\
$\begin{array}{l}\text { Females }(n=90) \\
\text { Mathematics section' }\end{array}$ & 347 & 3.4 & 3 \\
Males $(n=90)$ & 339 & 3.3 & 7 \\
Females $(n=83)$ & 349 & 3.4 & 10 \\
\hline
\end{tabular}

I. Mathematics $\chi^{2}=14.5, P<0.01$.

in the period 1931-1960. The school had by then been divided into two sections, humanities and mathematics, requiring these populations to be dealt with separately. All students in a given class followed the same curriculum and took the same tests. Most of the women chose the humanities section.

A third comparison was based on risk of illness among those who achieved the highest grades on the written final mathematics test in the mathematics and science section of Reykjavik College during the years 1931-1960. This examination required solutions of difficult problems in algebra, geometry, analytical geometry, trigonometry and calculus. All male students achieving a score of $90 \%$ or higher were included as index cases in the first study, as well as the four highest-scoring students in years when all marks fell below $90 \%$. Since the same problems cannot be used too frequently in the examinations, there is bound to be some variation in the difficulty of the test from year to year. A parallel second study has been made of all women achieving a grade of at least $40 \%$ on the written final. Only one woman scored above $90 \%$ in mathematics.

\section{RESULTS}

The initial survey, embracing the entire population born 1851-1940, is summarised in Table 1. As shown in the left half of the table, the 180 top male graduates, selected only on the basis of highest grade point averages, are expected to include 1.4 instances of hospital-treated psychosis if their risk equals that of the general population; the observed number is 4 (all cases of schizophrenia). Their 1016 first-degree relatives of both genders should include 8.4 cases of psychosis; the observed total is 22 ( 8 schizophrenia and 14 affective disorder). The study has also been reversed, assessing the numbers of previously identified patients with psychosis or their relatives (Karlsson, 1988) who are expected $(v$. observed) to be among the high performers, the population rate of top performance being about $0.1 \%$. The right-hand part of Table 1 shows that 4 patients among the 1377 documented total were top graduates (rather than 1.4), while the previously identified 9379 first-degree relatives of patients include 23 top graduates instead of a predicted 9.7. In this group there were 12 people with schizophrenia and 15 with an affective disorder. Using
Overall $\chi^{2}=20.3, P<0.01$. either approach, the rates are more than doubled in both index cases and close relatives.

The next survey (Table 2) centred around the three highest-scoring individuals (both male and female) in terms of average grades every year in either section of Reykjavik College graduating in the period 1931-1960. This equates to 90 persons in each group. However, since few female students chose the mathematics curriculum, that group is based on all 83 female graduates in that category in the same period. Five of the top-scoring males as well as two high-scoring females were later hospitalised with schizophrenia. The table includes parents and full siblings of the high performers, the expected rates of hospitalisation again being about $1 \%$ among these first-degree relatives. An increased risk over the expected value is seen only among relatives of those who chose the mathematics programme. In all the groups there were 11 people with schizophrenia and 13 with affective disorders.

The third comparison, summarised in Table 3, first evaluates the risk of psychosis in index cases and among close relatives of 90 male students who distinguished themselves as highest performers on the mathematics test at Reykjavik College in the period 1931-1960. Instead of the expected 4.3 instances of psychosis in the whole group there were 11 instances: 4 of schizophrenia and 7 of affective disorder. An evaluation of psychosis in families of 52 female graduates scoring at least $40 \%$ on the mathematics test revealed a similar pattern. Here two of the index individuals were diagnosed as having schizophrenia, and 3 of their 122 siblings as well as 3 of their 93 parents were treated for psychosis ( 2 schizophrenia and 4 affective disorder).

All the patients and their relatives surveyed in this study were identified in the earlier research on family risks of psychosis (Karlsson, 1988) without any intention at

Table 3 Rates of hospital-treated psychosis among able mathematicians and their close relatives

\begin{tabular}{|c|c|c|c|c|c|c|}
\hline \multirow[t]{2}{*}{ Relationship } & \multicolumn{3}{|c|}{ Male graduates } & \multicolumn{3}{|c|}{ Female graduates } \\
\hline & $n$ & Expected rate & Observed rate & $n$ & Expected rate & Observed rate \\
\hline Mathematicians & 90 & 0.7 & 3 & 52 & 0.4 & 2 \\
\hline Parents & 180 & 2.0 & I & 93 & I.I & 3 \\
\hline Full siblings & 185 & 1.6 & 7 & 122 & 1.0 & 3 \\
\hline
\end{tabular}


that time to investigate their academic performance. These people were seen only as potential carriers of psychosis genes.

\section{DISCUSSION}

The suggestion was first made by Huxley $e t$ al (1964) that psychotic disorders might be associated with some favourable effect, as this would explain their surprisingly high frequency in all human populations. Geneticists refer to such systems as balanced polymorphisms, mutant genes tending to exist at unexpectedly high levels if their heterozygous carriers benefit in some manner from the phenomenon of hybrid vigour.

Many years ago the claim was made that relatives of patients with psychosis exhibited a 'thought disorder' on the Lovibond Object Sorting psychological test (McConaghy, 1959). This report aroused a great deal of attention, and several investigators attempted to replicate its findings. The conclusion was that differences did indeed exist between the responses of control groups and those of patients' relatives, although less definitively than suggested by the original findings. When subsequently the principal author discovered that 'thought disordered' college students were often the high-performing members of their classes, the suggestion was made that the deviant responses should be designated 'allusive thinking', to avoid the negative implication of the former terminology (McConaghy \& Clancy, 1968). After that, interest in the subject dwindled.

More recently, other investigators have attempted to identify early signs of mental deviation in relatives of patients, suggesting that preventive treatment might be in order to intercept psychosis before the appearance of overt symptoms (Tsuang et al, 2000). Another research study conducted in Finland demonstrated that top male performers in middle school were at increased risk of subsequent development of psychotic illness (Isohanni et al, 1999). That study did not focus on the families of psychiatric patients.

\section{Present data}

The study reported here assesses the effect of psychosis factors on mental performance in affected families, using the unique opportunity existing in Iceland for demographic research. The investigation is aimed primarily at elucidation of the personality characteristics of relatives of people with psychotic disorders. The findings

\section{CLINICAL IMPLICATIONS}

- Increased knowledge of the basic biology of psychosis should make for better rapport with patients.

- New information may counteract negative opinions about people with mental illness and their families.

Facts reported here may encourage patients to comply with medication treatment.

\section{LIMITATIONS}

- The numbers reported here are relatively small, allowing statistical analysis only of the overall findings, not of specific subgroups.

- This kind of study needs to be repeated in other areas of the world where such data collection is possible.

- The investigation is restricted to good abilities present at age 20 years.

(First received I0 March 2003, final revision 3 November 2003, accepted 2 December 2003)

consistently indicate that healthy members of the families of people with psychosis often exhibit an advantage in academic performance.

The data in Table 1 leave little doubt that the altered levels of brain activity seemingly associated with risk of psychosis can lead to superior performance in academic settings. The top performers tend to be relatives of patients if they are not themselves psychosis-prone. Most of the individuals surveyed here lived in the period before the educational emphasis shifted to mathematics and science, but even in college subjects covered a century ago, an increase in psychosis was apparent among the gifted students.

Table 2 narrows down the fields in which individuals with high levels of brain arousal predominate. The risk of psychosis does not seem to appear in groups preparing for careers in languages, literature and jurisprudence, for example, but is more definitive in those headed for science or mathematics. High-performing women show evidence of being at risk of psychosis only when they seek careers requiring scientific skills.

In Table 3 high risks can be demonstrated in both men and women when the focus is specifically on mathematical reasoning. Men achieving grades of at least $90 \%$ or women with scores over $40 \%$ show elevated rates of psychosis in both the index cases and their relatives. These individuals were preparing for careers in mathematics, physics, chemistry, astronomy, engineering, architecture and medicine. The evidence reported in this paper supports the hypothesis that the elevated levels of mental stimulation encountered in families with psychosis may enhance creative forms of thinking.

\section{REFERENCES}

Goodwin, F. K. \& Jamison, K. R. (1990) Manic Depressive Illness. Oxford: Oxford University Press. Huxley, J., Mayr, E., Osmond, H., et al (1964) Schizophrenia as a genetic morphism. Nature, 204, 220-221.

Isohanni, I., Jarvelin, M.-R., Jones, P., et al (1999) Can excellent school performance be a precursor of schizophrenia? Acta Psychiatrica Scandinavica, 100, 17-26. Karlsson, J. L. (1974) Inheritance of schizophrenia. Acta Psychiatrica Scandinavica Supplementum, 247, I-116.

Karlsson, J. L. (1988) Partly dominant transmission of schizophrenia in Iceland. British Journal of Psychiatry, I52, 324-329.

Lange-Eichbaum, w. (1931) The Problem of Genius. London: Kegan Paul.

McConaghy, N. (1959) The use of an object sorting test in elucidating the hereditary factor in schizophrenia. Journal of Neurology, Neurosurgery and Psychiatry, 22 243-246.

McConaghy, N. \& Clancy, M. (1968) Familial relationship of allusive thinking in university students and their parents. British Journal of Psychiatry, I14, 1079-1089. Tsuang, M.T., Stone, W. S. \& Faraone, S.V. (2000) Toward reformulating the diagnosis of schizophrenia. American Journal of Psychiatry, 157, 1041-1050. 